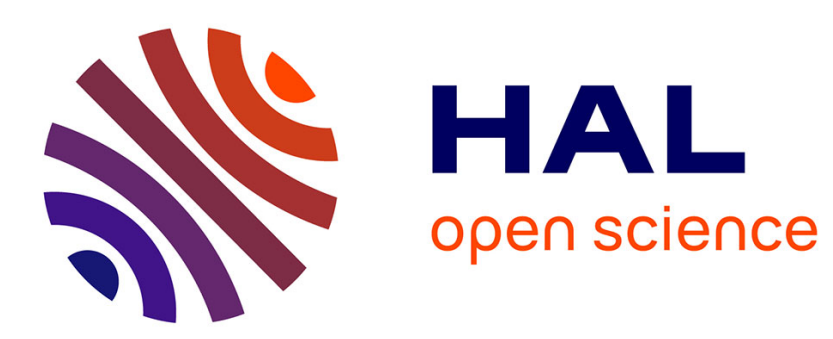

\title{
PROTON TRANSFERS IN HYDROGEN BONDED ORGANIC CRYSTALS AT LOW TEMPERATURES
}

\author{
M. Pierre, H. Trommsdorff
}

\section{To cite this version:}

M. Pierre, H. Trommsdorff. PROTON TRANSFERS IN HYDROGEN BONDED ORGANIC CRYSTALS AT LOW TEMPERATURES. Journal de Physique Colloques, 1987, 48 (C7), pp.C7-621-C7-623. 10.1051/jphyscol:19877150 . jpa-00226972

\section{HAL Id: jpa-00226972 https://hal.science/jpa-00226972}

Submitted on 1 Jan 1987

HAL is a multi-disciplinary open access archive for the deposit and dissemination of scientific research documents, whether they are published or not. The documents may come from teaching and research institutions in France or abroad, or from public or private research centers.
L'archive ouverte pluridisciplinaire HAL, est destinée au dépôt et à la diffusion de documents scientifiques de niveau recherche, publiés ou non, émanant des établissements d'enseignement et de recherche français ou étrangers, des laboratoires publics ou privés. 
JOURNAL DE PHYSIQUE

Colloque C7, supplément au $\mathrm{n}^{\circ} 12$, Tome 48, décembre 1987

PROTON TRANSFERS IN HYDROGEN BONDED ORGANIC CRYSTALS AT LOW TEMPERATURES

M. PIERRE and H.P. TROMMSDORFF

Laboratoire de spectrométrie physique, associé au CNRS et Celphyra, Université Scientifique. Technologique et Médicale de Grenoble, BP 87, F-38402 Saint-Martin-d'Hères Cedex, France

ABSTRACT The tunneling dynamics of protons involved in hydrogen bonds between carboxylic acid dimers is determined using picosecond transient grating techniques.

\section{INTRODUCTION}

The motion of a particle in a double well potential is a school book example of quantum mechanics. In a symmetric potential, tunneling through the barrier results in a splitting of the otherwise degenerate energy levels. The dynamical properties of such a two level system coupled to a heat bath have recently been in the focus of numerous theoretical investigations. Considering a gtatistical distribution of identical double wells, the question arises, for example. how the system reaches its thermal equilibrium after having been prepared in a state corresponding to the localization in one of the two wells. The object of this paper is to adress this issue by an experimental study on a model system.

\section{LEVEL STRUCTURE OF CARBOXYLIC ACID DIMERS}

Most carboxylic acids form dimers linked by two hydrogen bonds and there exist two tautomer forms, separated by potential barrier. which interconvert by a concerted two proton transfer along the hydrogen bonds. The low temperature behaviour of such systems, characterized by the condition that thermally activated barrier crossing no longer dominates the interconversion process, is of particular interest here. A condensed phase environment

differentiates the two wells and tends to localize the protons such that at low temperatures only the most stable tautomer exists. and it becomes difficult to appreciate the population relaxation. We have shown that the optical spectra of dyes are sensitive to the proton structure of the environment and can be used to access the dynamics of these systems at very low temperatures /1,2/. In one case the asymetry of the potential of the acid dimers next to a dye molecule is smaller than the tunneling splitting. This near degeneracy is lifted when the dye is electronically excited (see Fig.1). In an optical transition of the dye the system is projected from a set of delocalized onto a set of localized proton levels: the spectrum maps the energy spacings and the overlap of the two sets of wavefunctions. Inhomogeneous broadening prevents the resolution of the ground state level structure in conventional absorption spectra, and fluorescence line narrowing techniques have been used to determine this structure $13 /$. As in the crystal the dye molecule is caged between two equivalent acid dimers, four tunneling levels arising from two double well potentials of the the two dimers coupled to the dye are involved in the spectrum (see Fig.2). 

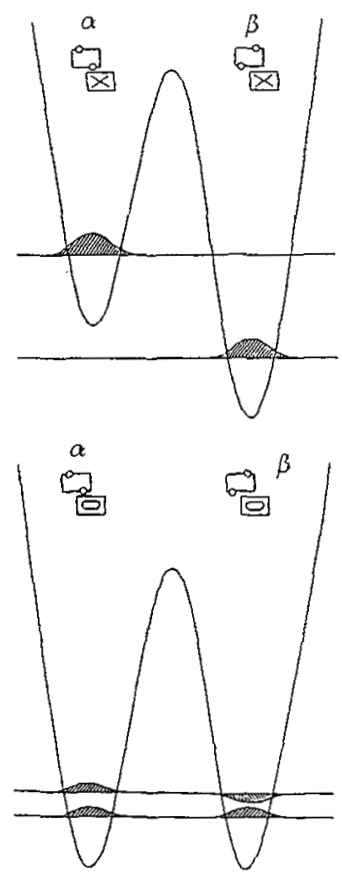

FIGURE 2
FIGURE 1

Schematic representation of the double well tautomerization potential of an acid dimer coupled to a dye molecule. The wavefunctions are indicated. The asymmetry of the double well potential changes when the dye molecule coupled to the dimer is excited.

Absorption (top) and line narrowed emission (bottom) spectra of the system studied here: The absorption spectra resolve the large asymmetry in the excited state but the ground state level structure is hidden in the inhomogeneous linewidth and is resolved only in the fluorescence line narrowed spectrum.

\section{TAUTOMERIZATION DYNAMICS}
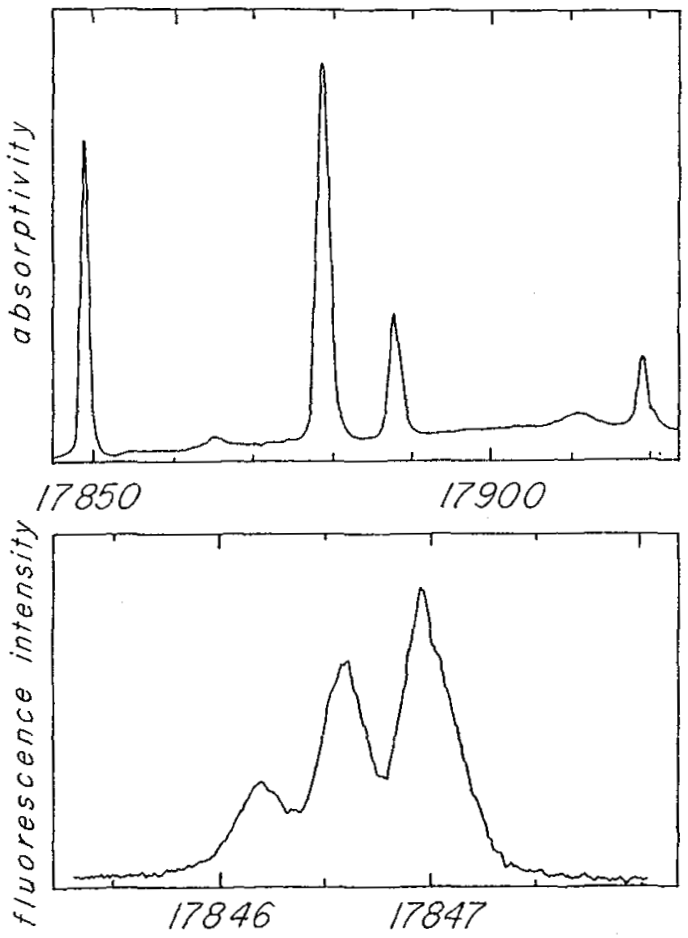

wavenumber

$c m^{-1}$

For the strongly asymmetric potential of a dimer near an excited dye the tautomerization dynamics can be determined in a straightforeward fashion from time resolved fluorescence measurements $/ 1,2 /$. These methods are inadequate to access the relaxation dynamics between the delocalized levels which are associated with the ground electronic state of the impurity, and time resolved picosecond transient grating techniques were used: In these experiments two time coincident laser 


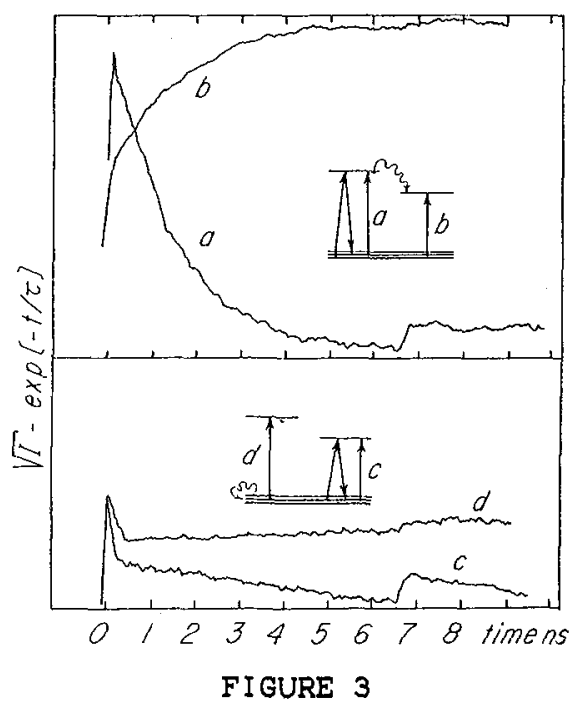

Transient grating measurements in a doped carboxylic acid crystal. The different pump and probe transitions are indicated:

tautomerization near an excited dye dominates the dynamics in the top curves, while in the bottom only the dynamics between the delocalized proton levels near the ground state impurity contribute to the signal. The peak near t=o reflects a fast process, possibly related to multiphoton excitation of higher electronic states.

pulses of equal frequency cross in the sample and form a pattern of interference fringes. This leads to a spatialiy periodic excitation and produces variations of the index of refraction, which have contributions from both the excited and ground state populations of the dye molecules. This index grating is probed by a time delayed third pulse, and the intensity of the diffracted signal. which is proportional to the square of the index variations, is measured as a function of the time delay. The square root of the signal therefore maps the time evolution of these populations.

Fig. 3 shows the results of such measurements: In the plot of the data the exponential decay of the excited state population of the dye has been substracted in order to emphasize the contribution by proton transfer to the population dynamics. The analysis of the data was made introducing a single relaxation rate: the value obtained for this rate $(3.5 \cdot 10+8$ sec-1) is in fair agreement with estimates obtained from the optical holeburning measurements. It is also of the same magnitude as measured in the case of strongly asymmetric potentials for the relaxation between localized levels $/ 1,2 \%$. This great insensitivity of the rate of relaxation to the asymmetry of the double well potential is surpriging and deserves further investigation and confirmation.

\section{REFERENCES}

/1/ J.M. Clemens, R.M. Hochstrasser, and H.P. Trommsdorff, J. Chem. Phys. 80 (1984) 1744.

/2/ G.R. Holtom, R.M. Hochstrasser, and H.P. Trommsdorff, Chem. Phys. Letters 131 (1986) 44.

/3/ R.M. Hochstrasser, and H.P. Trommsdorff, Chem. Phys, in press. 